\title{
Towards Water and Energy Self-Sufficiency: a Closed-Loop, Solar-Driven, Low-Tech Laundry Pilot Facility (LaundReCycle) for the Reuse of Laundry Wastewater
}

\author{
Devi Buehler ${ }^{1,2}$ (D) Nadine Antenen ${ }^{1} \cdot$ Matthias Frei $^{1} \cdot$ Christoph Koller $^{1}$ • \\ Diederik P. L. Rousseau ${ }^{2} \cdot$ Andreas Schoenborn $^{1} \cdot$ Ranka Junge $^{1}$
}

Received: 3 February 2021 / Accepted: 9 June 2021 / Published online: 12 July 2021

(C) The Author(s) 2021

\begin{abstract}
In the scope of this study, a pilot facility for the recycling of laundry effluent was developed and tested. With the aim to enable nearly complete energy and water selfsufficiency, the system is powered by a photovoltaic plant with second-life batteries, treats the wastewater within the unit and constantly reuses the treated wastewater for washing in a closed cycle. The technology for wastewater treatment is based on a lowtech approach consisting of a physical/mechanical pre-treatment and biological treatment in trickling filter columns. The treatment process is operated in batch mode for a capacity of five washing cycles per day. During five weeks of operation water quality, energy consumption and production, water losses and washing performance were monitored. The system recovered $69 \%$ of the used water for the washing machine while treating the wastewater to the necessary water quality levels. The average COD removal rate per cycle was $92 \%$. Energy analysis was based on modelled data of the monitored energy consumption. With the current set-up, an internal consumption rate of $80 \%$ and selfsufficiency of $30 \%$ were modelled. Future developments aim at increasing water and energy self-sufficiency and optimizing the water treatment efficiency.
\end{abstract}

Keywords Greywater treatment - Wastewater reuse - Laundry wastewater - Biological wastewater treatment $\cdot$ Self-sufficiency $\cdot$ Off-grid solar power

Devi Buehler

devi.buehler@zhaw.ch

1 Institute of Natural Resource Sciences, Zurich University of Applied Sciences, Grüentalstrasse 22, 8820 Wädenswil, Switzerland

2 Department of Green Chemistry and Technology, Ghent University, Campus Kortrijk, Sint-Martens-Latemlaan 2B, 8500 Kortrijk, Belgium 


\section{Introduction}

Freshwater is becoming an increasingly scarce resource due to global trends such as urbanization, climate change and population growth [1]. Therefore, the 2017 United Nations Global Water Report [1] highlights the importance of wastewater reuse as a strategy to address water scarcity. Since decentralized water systems not only reduce water consumption, but also increase resiliency of the water infrastructure network and reduce the costs of infrastructure replacement, they are often more sustainable than centralized water systems [2]. The local treatment and reuse of greywater is experiencing increased popularity because greywater (water from kitchen, bath and washing machine) is only lightly polluted compared to average municipal wastewater [3]. A number of studies have examined local greywater treatment and its reuse potential [4-9]. The greywater is typically treated to a quality level where it can be reused for non-potable purposes with lower quality requirements such as irrigation or toilet flushing [10-14]. The cascading use of the treated greywater has the potential to reduce freshwater demand and wastewater discharge. However, such systems nevertheless require suitable infrastructure to supply the freshwater and discharge the wastewater.

Washing machines use approximately $50 \mathrm{~L}$ water per washing cycle and are considered one of the most significant contributors of pollutants to greywater $[5,15]$. The reuse of laundry effluent could therefore be an important contribution to reduce the use of freshwater, as well as wastewater-associated problems such as pollution and eutrophication. Laundry effluent has different characteristics when compared to other greywater sources from bathroom and kitchen; for example, its chemical oxygen demand (COD) content is typically higher and more variable than for greywater from bathroom. Reported COD values in laundry effluent range between 58 and $4155 \mathrm{mg} / \mathrm{l}$ while for bathroom between 64 and $903 \mathrm{mg} / 1$ [13, 16-18]. The reported values for total suspended solids (TSS) in laundry wastewater range between 188 and $315 \mathrm{mg} / \mathrm{l}$, which is higher than for bathroom (58-78 mg/l) but lower than for kitchen $(134-625 \mathrm{mg} / \mathrm{l})$ [13, 16, 17]. Since many countries have banned the use of phosphate for laundry detergents, total phosphorus (TP) is typically low in laundry greywater [4], as are nitrogen concentrations [18]. Some studies even supplemented laundry greywater with nitrogen in order to achieve an optimal nutrient ratio for water treatment $[19,20]$. Mainly due to the alkalinity of most laundry detergents [21, 22], laundry wastewater typically has an alkaline $\mathrm{pH}[3,13]$.

Due to high fibre and surfactant concentrations as well as high and varying COD concentrations, the design of technologies for treating and reusing laundry effluent needs to be adapted to the characteristics of laundry wastewater. Hoinkis and Panten [23] developed a membrane bioreactor (MBR) in combination with reverse osmosis (RO) from pilot to large scale. Guilbaud et al. [24] used a direct nanofiltration process with tubular membranes for potential laundry wastewater recycling in a ship. Other high-tech approaches that have been tested to treat laundry wastewater include bipolar electrocoagulation-electroflotation [25]; coagulation [26]; membrane filtration [26]; moving bed bioreactor (MBBR) [20]; ultrafiltration [27]; activated carbon filtration [28]; vibrating shaker screen and tubular filtration [29]; a combination of ozone, catalyst and cavitation [30]; and a combination of coagulation, flocculation, dissolved air floatation, sand filtration, ozonation and GAC filtration [31]. Most of these systems were developed for implementation in industrial environments and typically require high capital and operating cost. Only little attention has been given to the design of low-cost and low-tech solutions, one exemption being Ahmad and EL-Dessouky [32], who developed a low-cost treatment system for the laundry of a petroleum refinery in Pakistan. The treatment process was based on a sand and gravel filter with three layers. The treated water, however, 
was ranked as low-grade water and was found to be only suitable for reuse in the first rinse of the dirty clothes [32]. However, in particular, low-tech and low-cost systems can be a practical solution to treat and reuse laundry wastewater on domestic scale in under-resourced areas.

This study examines a pilot low-tech laundry facility on domestic scale where the laundry effluent is treated within the unit and repeatedly reused for washing in a closed cycle. The system is based on mechanical pre-treatment, followed by biological treatment in trickling filter columns. Potential issues arising from a closed-loop recycling system were investigated, such as pollutant removal efficiency of the treatment steps, energy and water self-sufficiency and washing performance.

\section{Materials and Methods}

\section{Closed-Loop Pilot Laundry Facility}

The closed-loop pilot laundry facility was configured as a semi-batch system in which a laundry machine (Schulthess Spirit 530, Wolfhausen, Switzerland) was connected to two treatment steps (mechanical pre-treatment and biological treatment) with their respective water reservoirs (Fig. 1). The water reservoirs consisted of four tanks (Faserplast, Logistikbox, PE, Rickenbach, Switzerland), each comprising $300 \mathrm{~L}$ : wastewater tank, filter water tank, treated water tank and rainwater tank. Within the wastewater, filter water and treated water tank, there

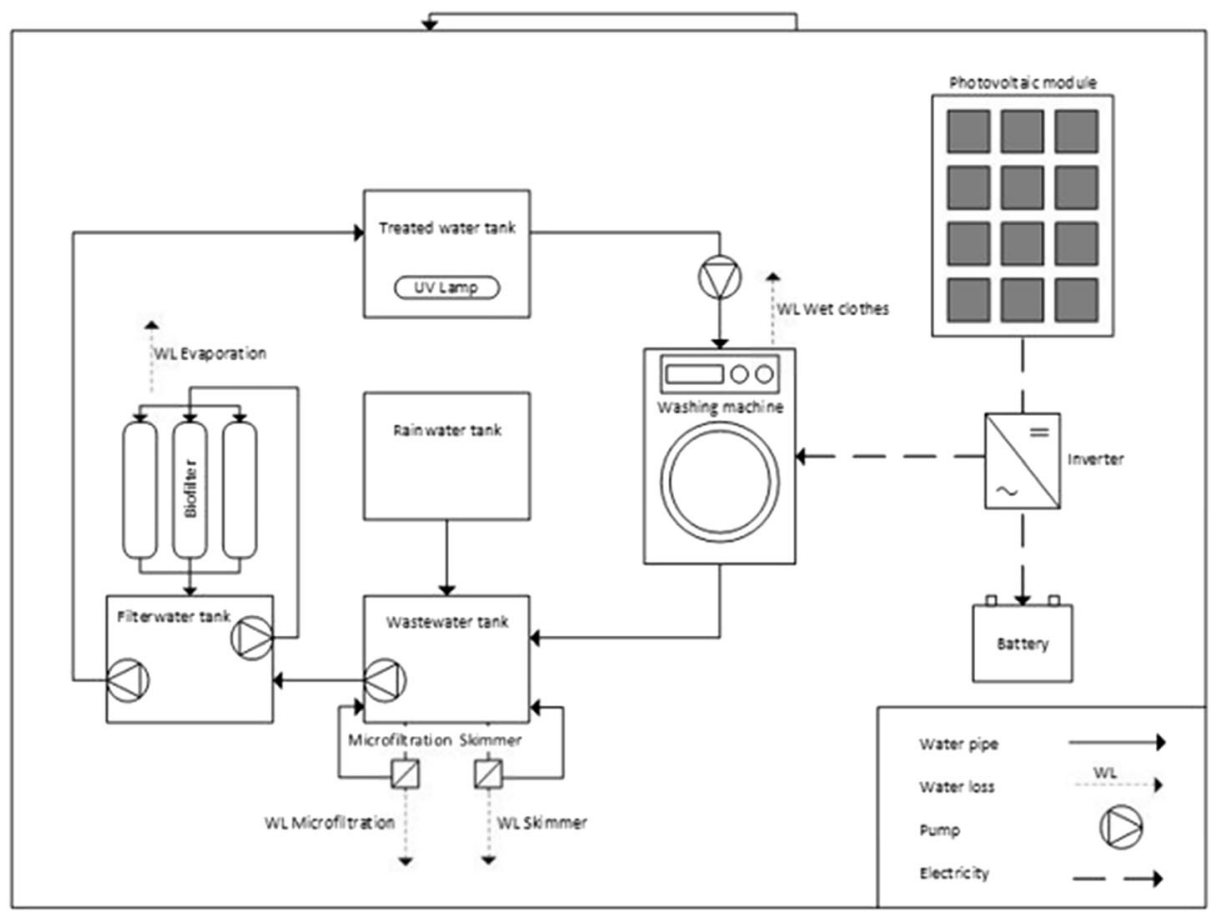

Fig. 1 Scheme of pilot facility for closed-loop recycling of laundry wastewater (LaundReCycle). The electricity of the photovoltaic plant is used for powering the washing machine as well as the pumps and filters of the treatment system 
were two alternating batches. Each batch contained a maximum of five washing cycles (approximately $50 \mathrm{~L}$ per cycle). The laundry machine obtained the water via a booster pump (Gardena, Hauswasserwerk 3000/4 eco, Mägenwil, Switzerland) from the treated water tank. The laundry effluent was discharged into the wastewater tank, from where the total batch was pre-treated. The pre-treatment consisted of a micro filtration step (Astralpool NanoFiber auto 200, Barcelona, Spain, mesh size 5-8 $\mu \mathrm{m}$ ) and a skimmer (Aqua Medic EVO 3000, Bissendorf, Germany) which run in parallel continuous circulation for a minimum of $19 \mathrm{~h}$ to treat the total batch of 5 wash cycles. The micro filtration eliminated fibres and particles, and the skimmer (Fig. 1: WL Micro filtration, WL Skimmer) removed excess detergent through small air bubbles which caused foaming, in order to prevent an overload of detergent to the biofilters. Subsequently, the entire pre-treated water was pumped from the wastewater tank to the filter water tank. Three biofilters (trickling filters/attached growth) in transparent columns (acrylic glass, self-made), each having a height of $100 \mathrm{~cm}$, diameter of $25 \mathrm{~cm}$ and volume of $49 \mathrm{~L}$ and filled with $30 \mathrm{~L}$ filter media, were operated in parallel at an average flow rate of $400 \mathrm{l} /$ $\mathrm{h}$ and removed the remaining particles, while the biofilm metabolized organic load (COD/ BOD) and assimilated nutrients. The filter media was non-sterile and not seeded with any microorganisms. After a minimum treatment of $24 \mathrm{~h}$, the batch was pumped into the treated water tank, from where it was reused for the next washing cycle. In this experiment, losses were refilled with rainwater from an external rainwater source (tap rainwater), directly fed into the treated water tank. The rainwater tank of the facility was not in use. The system design foresees that water losses can also be compensated by rainwater from the roof of the facility, which would be collected in the rainwater tank. Refill rainwater would be led into the wastewater tank, so that any contamination (pollen, solids) can be removed in the treatment process before water is reused for washing.

For the filter media in the trickling filter columns, a mix of perlite (Ricoter Erdaufbereitung AG, Switzerland, particle size 1-3 mm) and coco coir (ökohum GmbH, Switzerland) in proportion 3:1 (volume) was used. Prodanovic et al. [33] found that perlite, a medium with lower retention time, is mostly responsible for physico-chemical removal processes, while coco coir, a media with higher retention time, mostly enables biological removal processes. As a result, Prodanovic et al. [33] identified the combination of both as most suitable media for greywater treatment.

The pilot facility was powered by a $900 \mathrm{Wp}$ photovoltaic power plant with 12 CIGS thin-film modules (Type SL1-75F, Solibro GmbH, Germany) on the roof, coupled with battery storage. The modules covered a total area of $8.8 \mathrm{~m}^{2}$ and were installed at an angle of 10 degrees. For the batteries, reused second-life lithium-iron phosphate batteries (Type SE100AHA, Kyburz Switzerland AG) with a total of 4 $\mathrm{kWh}$ capacity were installed. For the inverter, a $5 \mathrm{~kW}$ on-grid InfiniSolar inverter (Voltronic Power, Taiwan) was used.

\section{Pilot Operation}

Prior to the experiment, the trickling filters were operated in a ramp up phase of three months with a total of 50 washing cycles to establish the biofilm of the biofilter. The experiment itself was carried out from 14/10/2019 to $15 / 11 / 2019$, running four washing cycles per day on three consecutive days of the week (Tuesday to Thursday). As a result, the water of batch A was reused eight times and of batch B seven times over the total experimental period of five weeks. For the laundry, a standardized washing load was used. Each load comprised eleven 100\% 
cotton T-shirts (Clique, Codogno LO, Italy) resulting in approximately $1.4 \mathrm{~kg}$ of dry weight per cycle. The experiment started with newly purchased white, coloured and black Tshirts, which were used for the whole duration of the experiment. The four daily washing cycles followed a pre-set colour arrangement of the shirts. The first laundry was always white, the second and third coloured and the fourth black. A standard soiling solution of $10 \mathrm{ml}$, adapted after Gotoh [34] and Rojvouranun [35] (Table 1), was added to the second, third and fourth washing cycle in order to recreate soiled laundry. Since the white laundry was not soiled, this allowed to identify a potential discoloration of the white laundry due to a potential coloration of the recycled water. For all washing cycles, the express wash program of approximately $40 \mathrm{~min}$ at $40^{\circ} \mathrm{C}$ and $30 \mathrm{ml}$ detergent Coop Oecoplan Flüssigwaschmittel Color Gel (Coop, Basel, Switzerland) were used. Table 2 shows the operating schedule of the first week of the experiment. This schedule was then repeated, as can be seen in the full operating schedule of the five-week experiment (Supplementary Information Table S1).

\section{Sampling and Analytical Methods}

On each washing day, seven water samples (50-ml tubes) from the different treatment steps (before and after water transfers, different batches A/B) were taken. Analyses of chemical oxygen demand COD (mg/l) and total phosphorus TP (mg/l) were performed with spectrophotometry (Hach, LCI400 for COD and LCK348 for TP); total nitrogen $\mathrm{TN}(\mathrm{mg} / \mathrm{l})$ and total organic carbon TOC $(\mathrm{mg} / \mathrm{l})$ were measured with a TOC/TN Analyzer (TOC-L Series (Combustion), Shimadzu). Turbidity (FNU, ISO 7027), pH, dissolved oxygen DO $(\mathrm{mg} / \mathrm{l})$, electrical conductivity EC $(\mu \mathrm{S} / \mathrm{cm})$ and temperature $\left({ }^{\circ} \mathrm{C}\right)$ were continuously logged with probes (Hach, Switzerland) in the wastewater, filter water and treated water tank. Furthermore, in each of these tanks, the water height (cm) was continuously logged with probes (Vega Messtechnik AG, Pfäffikon, Switzerland). To evaluate and ensure the cleaning performance of the detergent, once per week, three sets of AISE standard stains (AISE, Brussels, Belgium) were added to the white laundry and dried for a minimum of $24 \mathrm{~h}$ after washing. The washing performance was assessed with a camera-based multispectral colour measurement instrument (Mach 5, Colour Consult, the Netherlands). The energy consumption was monitored by the solar installation. Pathogens were not analysed, due to their unlikely or marginal presence in the type of wastewater used in the experiment. The exemplary sampling schedule of day 4 is shown in Table 3.

Table 1 Composition of standard soiling solution, adapted after Gotoh [34] and Rojvouranun [35]. Compounds for $1 \mathrm{~L}$ solution, of which $10 \mathrm{ml}$ were used per washing cycle

\begin{tabular}{ll}
\hline Ingredients & Amount (per 1 L tap water) \\
\hline Vegetable oil & $5 \mathrm{ml}$ \\
Apple cider vinegar & $5 \mathrm{ml}$ \\
Salt & $5 \mathrm{~g}$ \\
Cornstarch & $5 \mathrm{~g}$ \\
Soil & $5 \mathrm{~g}$ \\
Charcoal & $5 \mathrm{~g}$ \\
Detergent (emulsifier) & $5 \mathrm{ml}$ \\
\hline
\end{tabular}


Table 2 Operating schedule of week 1 of the five-week experiment

\begin{tabular}{|c|c|c|c|c|c|c|c|}
\hline \multirow{2}{*}{ Week } & \multirow{2}{*}{ Day } & \multirow{2}{*}{ Batch } & \multicolumn{5}{|c|}{ Time } \\
\hline & & & $08: 00$ & 09:00 & $10: 00$ & $11: 00$ & $12: 00-8: 00$ \\
\hline \multirow{13}{*}{1} & 1 & & & & & & \\
\hline & \multirow{2}{*}{2} & A & 1 & & & & \\
\hline & & $\mathrm{B}$ & & & & & \\
\hline & \multirow{2}{*}{3} & $A$ & & & & & \\
\hline & & B & 1 & & & & \\
\hline & \multirow{2}{*}{4} & A & 2 & & & & \\
\hline & & $\mathrm{B}$ & & & & & \\
\hline & \multirow{2}{*}{5} & $\mathrm{~A}$ & & & & & \\
\hline & & $\mathrm{B}$ & & & & & \\
\hline & \multirow{2}{*}{6} & $A$ & & & & & \\
\hline & & $\mathrm{B}$ & & & & & \\
\hline & \multirow[t]{2}{*}{7} & A & & & & & \\
\hline & & B & & & & & \\
\hline
\end{tabular}

White laundry without soiling

Coloured laundry with added standard soiling

Black laundry with added standard soiling

Pre-treatment

Biological treatment

Number of times water is reused

AISE standard stains added to laundry

\section{Data Analysis}

Removal rates are calculated according to Eq. 1 , where $W_{\text {raw }}$ and $W_{\text {treat }}$ denote mean concentrations of investigated substances in the raw wastewater and in the effluent of the treatment steps, respectively.

$$
\text { Removal }[\%]=100-\frac{100 * W_{\text {treat }}}{W_{\text {raw }}}
$$

Energy analysis was based on modelled data of the monitored energy consumption of a standard washing day. The values of the monitored energy consumption were imported into the software Polysun (Vela Solaris AG, Winterthur, Switzerland). Polysun was used to model the following values and performance indicators: annual solar production $\mathrm{AC}(\mathrm{kWh})$, total annual consumption $(\mathrm{kWh})$, self-consumption $(\%)$ and self-sufficiency (\%). The selfconsumption is the self-consumed part of the solar production relative to the total solar production [36]. It indicates to what degree the produced solar energy can be directly consumed by the system. The self-sufficiency is the self-consumed part of the solar production relative to the total consumption of the system. It indicates to what degree the on-site generation is sufficient to cover the total energy demand of the system [36]. The values were modelled for the current configuration and operation of the system, as well as for optimized scenarios. As a realistic scenario, four washing days per week, with four washings per washing day, were assumed.

Table 3 Sampling schedule on day 4 of the experiment

\begin{tabular}{|c|c|c|c|c|c|c|c|}
\hline $\begin{array}{l}\text { Daily schedule } \\
\text { (example day } 4 \text { ) }\end{array}$ & $07: 55$ & 08:00 & 08:05 & 08:10 & 08:20 & $13: 00$ & $17: 00$ \\
\hline
\end{tabular}

Sample biofilter

Transfer biofilter $\rightarrow$ freshwater

Sample freshwater

Sample wastewater

Transfer wastewater $\rightarrow$ biofilter

4 washing cycles

Sample wastewater

Sample biofilter

Sample wastewater

Sample biofilter
A* 1**

$$
\mathrm{A} 1 \rightarrow \mathrm{A} 2 * *
$$

A 2

B* 1

A 2

A 2

B 1

A 2

B 1

*A / B: Name of the two alternating batches; **1/2: Number of times water is reused 
The water balance was calculated based on the monitored water levels. The water volume was calculated from the water levels and the tank size (length, $93 \mathrm{~cm}$; width, $59 \mathrm{~cm}$ ). The respective differences in water levels indicated the water losses.

To evaluate the washing performance, the method of AISE [37] was used. The method is based on the y-values of the colour coordinates. One performance test was based on three sets of stains, where each stain was measured twice. For each stain, the mean value of all measurements was calculated. To calculate the overall washing performance, the mean values of all 14 stains were summed up.

\section{Results}

\section{Pollutant Removal}

Water quality parameters were monitored in the laundry effluent, after pre-treatment, after the biofilter and in the treated water. The treated water was composed of the filter water from the biofilter, mixed with refill tap rainwater to compensate for the water losses. The mean water temperature in the system ranged from $13.1^{\circ} \mathrm{C}$ after the pre-treatment up to $16.4^{\circ} \mathrm{C}$ after the biofilter (Table 4). The system achieved an overall COD removal of $91 \%$, with the largest removal (72\%) due to the pre-treatment (Table 4). The treated water reached a final average value for COD of 28.3 $\mathrm{mg} / \mathrm{l}$ (Table 4). Turbidity was reduced by a total of $75 \%$ (58\% in pre-treatment) reaching a final mean value of 5.4 FNU. Nutrient concentrations were very low but for TN still above the limit of detection. With repeated reuse of the treated water, COD, TOC and turbidity in the treated water tank gradually increased over the five weeks (Fig. 2). At the end of the experiment, there was a rather sharp increase in concentrations, which coincided with a water temperature drop to $8.6^{\circ} \mathrm{C}$ due to cold weather.

\section{Energy Analysis (Model Based)}

With the described design and operation at the location in Wädenswil, Switzerland, the model calculated a self-consumption of $80 \%$ and self-sufficiency of $30 \%$ (Table 5). Most of the

Table 4 Mean and standard deviation of abiotic parameters in the different treatment steps and their removal percentages after pre-treatment and after total treatment during the five weeks experimental period

\begin{tabular}{|c|c|c|c|c|c|c|c|}
\hline \multirow[t]{2}{*}{ Parameter } & \multirow[t]{2}{*}{ Unit } & \multirow{2}{*}{$\begin{array}{l}\text { Input water, recycled* } \\
(\mathrm{n}=14)\end{array}$} & \multirow{2}{*}{$\begin{array}{l}\text { Laundry effluent } \\
(\mathrm{n}=14)\end{array}$} & \multicolumn{2}{|c|}{ After pre-treatment } & \multicolumn{2}{|l|}{ After biofilter } \\
\hline & & & & $(n=14)$ & $(\%)$ & $(\mathrm{n}=15)$ & $(\%)^{* *}$ \\
\hline COD & $\mathrm{mg} / 1$ & $19.5 \pm 10.9$ & $318.4 \pm 40.7$ & $88.9 \pm 45.2$ & 72 & $28.3 \pm 16.4$ & 91 \\
\hline TOC & $\mathrm{mg} / \mathrm{l}$ & $7.5 \pm 4.7$ & $55.2 \pm 16.9$ & $21.4 \pm 8.8$ & 61 & $11.0 \pm 5.5$ & 80 \\
\hline $\mathrm{TN}$ & $\mathrm{mg} / \mathrm{l}$ & $0.4 \pm 0.2$ & $0.7 \pm 0.5$ & $0.3 \pm 0.1$ & 57 & $0.2 \pm 0.03$ & 71 \\
\hline $\mathrm{TP}$ & $\mathrm{mg} / \mathrm{l}$ & $<0.03$ & $<0.03$ & $<0.03$ & - & $<0.03$ & - \\
\hline Turbidity & FNU & $1.2 \pm 2.3$ & $21.5 \pm 5.6$ & $9.1 \pm 4.5$ & 58 & $5.4 \pm 1.8$ & 75 \\
\hline $\mathrm{pH}$ & & $6.9 \pm 0.1$ & $6.9 \pm 0.1$ & $6.9 \pm 0.06$ & I & $6.9 \pm 0.0$ & I \\
\hline $\mathrm{EC}$ & $\mu \mathrm{S} / \mathrm{cm}$ & $380.7 \pm 45.8$ & $464.5 \pm 30.1$ & $341 \pm 88.2$ & / & $437.9 \pm 72.7$ & I \\
\hline DO & $\mathrm{mg} / \mathrm{l}$ & $11.3 \pm 1.1$ & $9.69 \pm 3.3$ & $10.84 \pm 0.9$ & / & $9.1 \pm 1.6$ & I \\
\hline Temp & ${ }^{\circ} \mathrm{C}$ & $13.4 \pm 2.1$ & $15.9 \pm 4.7$ & $13.1 \pm 3.7$ & I & $16.4 \pm 1.4$ & I \\
\hline
\end{tabular}

*Treated water after biofilter mixed with tap rainwater from refill, measured in the treated water tank ${ }^{* *}$ Cumulative removal percentage of both treatment steps 


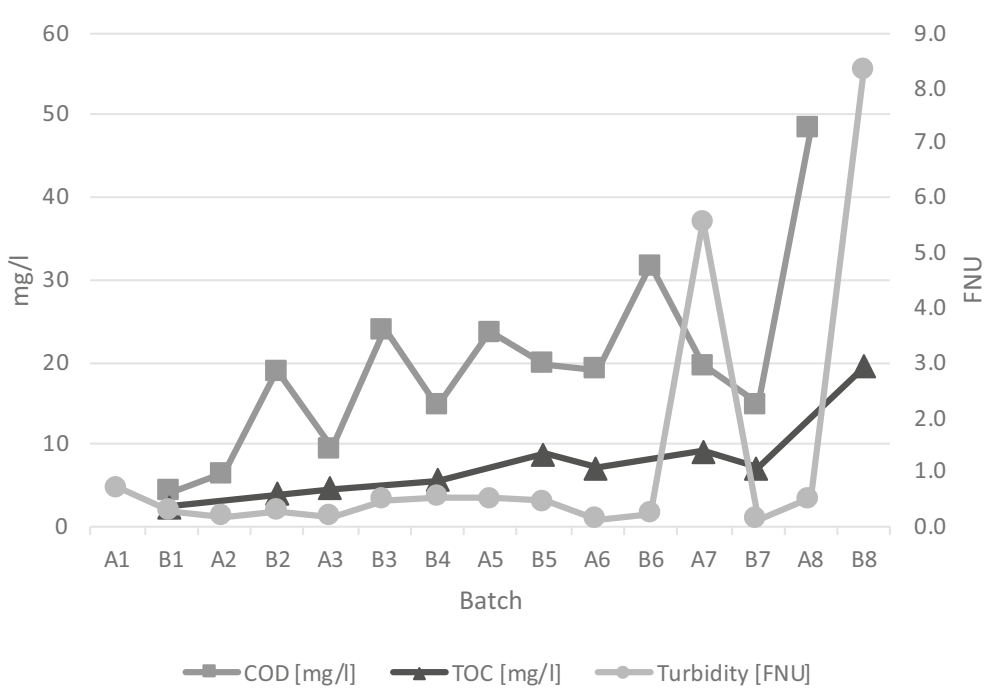

Fig. 2 Development of COD/TOC concentrations and turbidity in two alternating batches (A/B) over the experimental period of 5 weeks in the treated water tank

energy (78\%) was used by the pumps and filters for the water treatment, since these were continuously running. Also, the PV module area was rather undersized for this installation. Therefore, a set of optimization measures were implemented into the software. These included the following: intermittent pump/filter operation, double the size of the module area and time of washing at midday instead of morning. By implementing these measures at the location in Switzerland, self-sufficiency could be increased to 66\% (Table 5). Since the target market for the LaundReCycle is in arid regions with water scarcity, the simulation was also performed for Cape Town, South Africa. In South Africa, the solar radiation is 66\% higher than in Switzerland. In combination with all optimization measures, self-sufficiency of $86 \%$ could be achieved.

\section{Water Balance}

The analysis of the water balance over the duration of the whole experiment showed that $69 \%$ of the used freshwater entering the washing machine was reused at the end of the treatment.

Table 5 Modelled performance for one year based on monitored data, and optimized scenarios in Switzerland and South Africa

\begin{tabular}{|c|c|c|c|}
\hline Performance indicator & $\begin{array}{l}\text { Pilot configuration, } \\
\text { Switzerland }\end{array}$ & $\begin{array}{l}\text { Optimized configuration, } \\
\text { Switzerland }\end{array}$ & $\begin{array}{l}\text { Optimized configuration, } \\
\text { South Africa }\end{array}$ \\
\hline Annual solar production $\mathrm{AC}$ & $1002 \mathrm{kWh}$ & $1722 \mathrm{kWh}$ & $2438 \mathrm{kWh}$ \\
\hline Total annual consumption & $2706 \mathrm{kWh}$ & $1579 \mathrm{kWh}$ & $1542 \mathrm{kWh}$ \\
\hline $\begin{array}{c}\text { Annual consumption } \\
\text { washing machine }\end{array}$ & $605 \mathrm{kWh}$ & $605 \mathrm{kWh}$ & $605 \mathrm{kWh}$ \\
\hline $\begin{array}{l}\text { Annual consumption water } \\
\text { treatment }\end{array}$ & $2102 \mathrm{kWh}$ & $974 \mathrm{kWh}$ & $937 \mathrm{kWh}$ \\
\hline Self-consumption & $80 \%$ & $58 \%$ & $53 \%$ \\
\hline Self-sufficiency & $30 \%$ & $66 \%$ & $86 \%$ \\
\hline
\end{tabular}


The largest fraction (26\%) was lost in the pre-treatment, and specifically in the skimmer, while evaporation losses $(2 \%)$ and withdrawal of wet clothes $(3 \%)$ played a minor role. These calculations do not include the use of rainwater from the roof of the facility, which could significantly improve the overall water balance. In this case, the collection of rainwater would be regarded as a gain inside the system boundary, as defined by Buehler et al. [38].

\section{Washing Performance}

The mean cumulative AISE washing performance was 808 with a standard deviation of 11 . Thus, the washing performance was subject to rather large fluctuations, while no major deviations on the individual stains were observed. There was no clear trend towards better or worse washing performance over the five-week period. High performance washing detergents typically achieve AISE values of 1000 and higher. However, in this experiment, other washing settings were applied; therefore, the results are not comparable to other washing tests but only within themselves.

\section{Discussion}

The pilot operation of the LaundReCycle showed that the low-tech design achieved COD removal comparable to other studies (Table 6). Typical high-tech approaches achieve COD removal between 87 and $99 \%$. The $91 \%$ COD removal of the low-tech approach in this study lies in the range of the high-tech approaches. In comparison, Ahmad and EL-Dessouky [32] did not achieve any COD removal with the low-tech sand and gravel filter. However, removal of turbidity in this study (75\%) was in the range of Ahmad and EL-Dessouky [32] (Table 6). Since nutrient concentrations in the laundry effluent were very low $(0.7 \mathrm{mg} / \mathrm{l} \mathrm{TN},<0.03 \mathrm{mg} / 1$ $\mathrm{TP}$ ), comparison of removal rates is likely not expressive. Other studies report values from 2.8 to $40 \mathrm{mg} / \mathrm{l}$ for TN and 0.2 to $51.6 \mathrm{mg} / \mathrm{l}$ for TP $[13,17,18,23]$. The $\mathrm{pH}$ of 6.9 was almost neutral. This is in contrast to predominantly alkaline $\mathrm{pH}$ values between 7.5 and $11[13,16-20$, $23,25,26,32,39-42]$. Some studies, however, also reported nearly neutral $\mathrm{pH}$ values between 7 and 7.2 [24, 31], and some even acidic $\mathrm{pH}$ between 3.3 and $6.8[18,43]$, possibly due to relatively high concentrations of organic acids [18]. The rather neutral $\mathrm{pH}$ of this study could be a result of the use of rainwater or a certain composition of the detergent. Laundry effluent typically has high variations in COD [18]. The COD concentration $(318 \mathrm{mg} / \mathrm{l})$ was in the same range of studies with lightly polluted laundry effluent (Table 6) [26, 32]. However, most studies report higher COD values between 582 and $1700 \mathrm{mg} / \mathrm{l}$ (Table 6) [19, 20, 23, 24, 31, 44]. The same pattern can be seen for TOC and turbidity. The laundry effluent of this study can therefore be classified as lightly polluted. Hence, to better test the treatment performance of the facility, it is necessary to increase soiling of the laundry by adapting the standard soiling solution in Table 1.

So far, no other study used biological trickling filters for the treatment of laundry effluent. According to Zhang et al. [45], natural ventilation trickling filters for the treatment of municipal wastewater have been receiving increased attention in recent years. Trickling filters do not require any active aeration or sophisticated equipment, and therefore have the potential to achieve high treatment efficiency while keeping operating and capital costs low $[45,46]$. Chang et al. [47] underline that attached biofilm growth on a filter media allows for higher concentrations of active biomass than in suspended growth activated sludge systems, which 


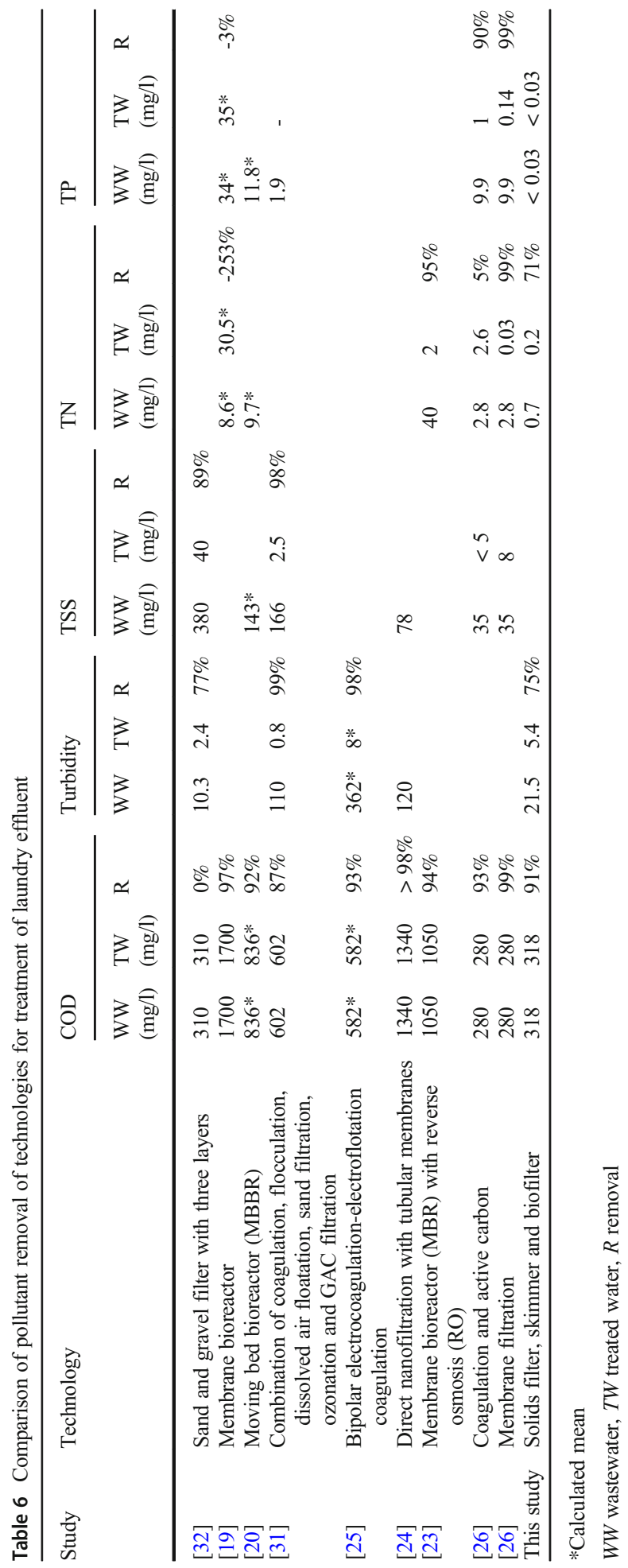


allows reducing the size of the reactor. Moreover, the filter medium can act as an additional physical filter by adsorption [47]. In fact, it is unclear to what extent the biofilter performance in this study is based on biological or physical treatment processes. During the ramp up phase, considerable COD removal was already observed after the first cycle (data not shown), before any biofilm could have been established. To optimize the system design and the biofilter in particular, further investigations on the physical processes (adsorption isotherms) and microbial communities in the biofilter are needed. Since biofilms widely occur in the washing machines themselves, Gattlen et al. [44] suggest using these microbial communities for the wastewater treatment, as these have already adapted to the chemical and mechanical pollution in laundry effluent. On the other hand, Jabornig and Favero [7] show that prior inoculation with microorganisms has no influence on the biofilm build-up time.

Treating laundry effluent with biological processes is in particular challenging regarding the wide variation of nutrient concentration of laundry wastewater [10, 17]. Nutrient concentrations mainly depend on the type and amount of soiling on the laundry, ranging from only lightly stained clothes to heavily polluted laundry from industrial environments. Both extremes can pose a risk to the biofilter. Too low nutrient concentrations can lead to an undersupply of the biofilter, resulting in a reduced treatment performance [48]. On the other hand, too high nutrient concentrations might exceed the treatment capacity of the biofilter. Should undersupply of nutrient limit the performance of the biofilter, nutrients could be added to the biofilter as this has been done with nitrogen in other studies [19, 20].

The development of COD, TOC and turbidity over the duration of the experiment (Fig. 2) indicated a gradual increase of these parameters with a considerable leap in the last batch. Possible explanations could be the temperature drop inhibiting biological processes, clogging of the micro filtration, the saturation of the biofilter due to COD adsorption, given that the process is present, or sloughing of the biofilter. However, due to the near absence of phosphorous TP (Table 4), biofilm growth could have been limited as a result of nutrient undersupply. Nevertheless, biological processes could have still taken place due to potentially leaking nutrients from coco coir. Should future long-term operation lead to sloughing of the biofilter, a removal system, such as a settler, would need to be installed.

The aim of the LaundReCycle is to operate as a water and energy self-sufficient closed-loop system. An important aspect of closed-loop systems is the potential of accumulating substances. Accumulations have been observed in other closed-loop systems such as recirculating aquaculture systems [49] or in hydroponics [50], where nitrate respectively salt typically accumulate over time. In the scope of this study, the treated laundry effluent was repeatedly reused for the next washing. As a result, the two batches were recycled seven and eight times respectively. The average concentration for COD in the treated water was $28 \mathrm{mg} / \mathrm{l}$. This value was always below defined limit values for laundry water from literature $(50 \mathrm{mg} / \mathrm{l}$ [3], $100 \mathrm{mg} / \mathrm{l}$ [31], $150 \mathrm{mg} / 1$ [23]) but showed an increase over time. In addition, water losses were rather high $(31 \%)$, meaning the same amount was refilled with tap rainwater, resulting in dilution of pollutant concentrations and lower values in the treated water. This illustrates that the level of water self-sufficiency has a counteractive effect on the pollutant concentration in the treated water. While future developments should aim to reduce water losses and increase recovery, special attention should be drawn to the investigation sufficient pollutant removal and potential accumulations over time. Such accumulations will likely be managed by exchanging part of the water, same as this is done in most circulating water systems. Another possible measure might be the use of non-ionic surfactants, regarding ions, combined with a well-adapted microbial flora in the biofilter to reduce the extent of required water exchange. 
Furthermore, hygiene is an important factor when it comes to water reuse. Dolnicar et al. [51] have identified health concerns as one of the main factors when it comes to acceptability of water reuse. The design of the LaundReCycle incorporates a UV lamp for disinfection of the treated wastewater. However, in this study, the UV lamp was not yet included, because due to the type of soiling used in the experiment, the presence of coliforms was very unlikely. Therefore, the monitoring of hygiene parameters and the effectiveness of the UV lamp need to be studied. To achieve representative pathogen loads in the wastewater, the standard soiling solution needs to be adapted accordingly. Moreover, it should be taken into account that the UV lamp will increase the energy consumption.

Energy self-sufficiency could be optimized by implementing the proposed optimization measures. Further optimization measures include cold washing, if accepted by the user, turning off water treatment pumps once treatment goal is achieved, use more efficient pumps and use of eco washing program if longer washing times are acceptable. Furthermore, the used detergent is a crucial element. The faster and better its biodegradability, the higher pollutant removal can be achieved. Water selfsufficiency could be optimized by using rainwater from the roof of the facility and recovering losses. Particularly, the losses of the skimmer could either be reclaimed or the skimmer could be turned off completely and only used as back-up filter should the load on the biofilter be too high. Green walls for wastewater treatment $[9,33,52,53]$ could be used to treat the by-products from the skimmer and the filters and potentially reclaim these water losses. By implementing these measures, it is feasible that the system could be operated completely water and energy self-sufficiently, depending on the rainfall and solar radiation of the respective location.

\section{Conclusion}

In the scope of this study, the pilot facility for the recycling of laundry effluent (LaundReCycle) was operated and monitored during five weeks. The experimental design allowed to analyse a range of parameters in order to gain first insights into the performance and feasibility of the facility. Even though sufficient removal rates were achieved, a detailed understanding of the functionality of the biofilter is still missing. In order to achieve complete energy and water self-sufficiency while fulfilling hygiene requirements and sufficient pollutant removal, the system needs to be further optimized and evaluated, especially in regard to crucial parameters such as pathogens and accumulations over time. To better test the performance of the system, it is necessary to adapt the standard soiling solution to achieve representative pollution levels of the laundry effluent. The final aim is to implement the LaundReCycle in water-scarce and under-resourced areas. In this context, the next step should be to test the system under real-life conditions in terms of technical performance regarding the local climate conditions, as well as economic feasibility and social integration.

Supplementary Information The online version contains supplementary material available at https://doi.org/ $10.1007 /$ s43615-021-00077-2.

Availability of Data and Material Not applicable.

Code Availability Not applicable. 
Author Contribution Conception and design were performed by Devi Buehler, Nadine Antenen, Matthias Frei, Ranka Junge, Christoph Koller and Andreas Schoenborn. Material preparation, data collection and analysis were performed by Devi Buehler, Nadine Antenen and Christoph Koller. The first draft of the manuscript was written by Devi Buehler. Nadine Antenen, Ranka Junge, Diederik Rousseau and Andreas Schönborn commented on previous versions of the manuscript. All authors read and approved the final manuscript.

Funding Open Access funding provided by ZHAW Zürcher Hochschule für Angewandte Wissenschaften. The study was funded by seed-funding from Zurich University of Applied Sciences.

\section{Declarations}

Ethics Approval No approval of research ethics committees was required to accomplish the goals of this study.

Consent to Participate Informed consent was obtained from all individual participants included in the study.

Consent for Publication Informed consent was obtained from all individual participants included in the study.

Conflict of Interest The authors declare no competing interests.

Open Access This article is licensed under a Creative Commons Attribution 4.0 International License, which permits use, sharing, adaptation, distribution and reproduction in any medium or format, as long as you give appropriate credit to the original author(s) and the source, provide a link to the Creative Commons licence, and indicate if changes were made. The images or other third party material in this article are included in the article's Creative Commons licence, unless indicated otherwise in a credit line to the material. If material is not included in the article's Creative Commons licence and your intended use is not permitted by statutory regulation or exceeds the permitted use, you will need to obtain permission directly from the copyright holder. To view a copy of this licence, visit http://creativecommons.org/licenses/by/4.0/.

\section{References}

1. UNESCO (2017) The United Nations world water development report, 2017: Wastewater: the untapped resource

2. Makropoulos CK, Butler D (2010) Distributed water infrastructure for sustainable communities. Water Resour Manag 24:2795-2816. https://doi.org/10.1007/s11269-010-9580-5

3. Gross A, Alfiya Y, Friedler E (2015) Greywater Reuse. CRC Press

4. Chrispim MC, Nolasco MA (2017) Greywater treatment using a moving bed biofilm reactor at a university campus in Brazil. J Clean Prod 142:290-296. https://doi.org/10.1016/j.jclepro.2016.07.162

5. Gross A, Shmueli O, Ronen Z, Raveh E (2007) Recycled vertical flow constructed wetland (RVFCW) - a novel method of recycling greywater for irrigation in small communities and households. Chemosphere 66 : 916-923. https://doi.org/10.1016/j.chemosphere.2006.06.006

6. Hernández Leal L, Zeeman G, Temmink H, Buisman C (2007) Characterisation and biological treatment of greywater. Water Sci Technol 56:193-200. https://doi.org/10.2166/wst.2007.572

7. Jabornig S, Favero E (2013) Single household greywater treatment with a moving bed biofilm membrane reactor (MBBMR). J Membr Sci 446:277-285. https://doi.org/10.1016/j.memsci.2013.06.049

8. Li Z, Gulyas H, Jahn M, Gajurel DR, Otterpohl R (2004) Greywater treatment by constructed wetlands in combination with $\mathrm{TiO} 2$-based photocatalytic oxidation for suburban and rural areas without sewer system. Water Sci Technol 48:101-106. https://doi.org/10.2166/wst.2004.0815

9. Masi F, Bresciani R, Rizzo A, Edathoot A, Patwardhan N, Panse D, Langergraber G (2016) Green walls for greywater treatment and recycling in dense urban areas: a case-study in Pune. J Water Sanit Hyg Dev 6: 342-347. https://doi.org/10.2166/washdev.2016.019

10. Li F, Wichmann K, Otterpohl R (2009) Review of the technological approaches for grey water treatment and reuses. Sci Total Environ 407:3439-3449. https://doi.org/10.1016/j.scitotenv.2009.02.004

11. Maimon A, Gross A (2018) Greywater: limitations and perspective. Curr Opin Evironmental Sci Health 2:1-6 
12. March JG, Gual M, Orozco F (2004) Experiences on greywater re-use for toilet flushing in a hotel (Mallorca Island, Spain). Desalination 164:241-247. https://doi.org/10.1016/S0011-9164(04)00192-4

13. Noutsopoulos C, Andreadakis A, Kouris N, Charchousi D, Mendrinou P, Galani A, Mantziaras I, Koumaki E (2018) Greywater characterization and loadings - physicochemical treatment to promote onsite reuse. J Environ Manag 216:337-346. https://doi.org/10.1016/j.jenvman.2017.05.094

14. Zhu J, Wagner M, Cornel P, Chen H, Dai X (2018) Feasibility of on-site grey-water reuse for toilet flushing in China. J Water Reuse Desalination 8:1-13. https://doi.org/10.2166/wrd.2016.086

15. Pakula C, Stamminger R (2015) Energy and water savings potential in automatic laundry washing processes. Energy Effic 8:205-222. https://doi.org/10.1007/s12053-014-9288-0

16. Friedler E (2004) Quality of individual domestic greywater streams and its implication for on-site treatment and reuse possibilities. Environ Technol 25:997-1008. https://oi.org/10.1080/09593330.2004.9619393

17. Ghaitidak DM, Yadav KD (2013) Characteristics and treatment of greywater - a review. Environ Sci Pollut Res 20:2795-2809. https://doi.org/10.1007/s11356-013-1533-0

18. Shaikh IN, Ahammed MM (2020) Quantity and quality characteristics of greywater: a review. J Environ Manag 261:110266. https://doi.org/10.1016/j.jenvman.2020.110266

19. Andersen M, Kristensen GH, Brynjolf M, Grüttner H (2002) Pilot-scale testing membrane bioreactor for wastewater reclamation in industrial laundry. Water Sci Technol 46:67-76. https://doi.org/10.2166/wst. 2002.0553

20. Bering S, Mazur J, Tarnowski K, Janus M, Mozia S, Morawski AW (2018) The application of moving bed bio-reactor (MBBR) in commercial laundry wastewater treatment. Sci Total Environ 627:1638-1643. https://doi.org/10.1016/j.scitotenv.2018.02.029

21. Gani P, Sunar NM, Matias-Peralta HM, Abdul Latiff AA, Kamaludin NS, Parjo UK, Emparan Q, Er CM (2015) Experimental study for phycoremediation of Botryococcus Sp. on greywater. Appl Mech Mater 773774:1312-1317. https://doi.org/10.4028/www.scientific.net/AMM.773-774.1312

22. Oteng-Peprah M, Acheampong MA, deVries NK (2018) Greywater characteristics, treatment systems, reuse strategies and user perception-a review. Water Air Soil Pollut 229:255. https://doi.org/10.1007/s11270018-3909-8

23. Hoinkis J, Panten V (2008) Wastewater recycling in laundries-from pilot to large-scale plant. Chem Eng Process Process Intensif 47:1159-1164. https://doi.org/10.1016/j.cep.2007.12.010

24. Guilbaud J, Massé A, Andrès Y, Combe F, Jaouen P (2010) Laundry water recycling in ship by direct nanofiltration with tubular membranes. Resour Conserv Recycl 55:148-154. https://doi.org/10.1016/j. resconrec.2010.09.001

25. Ge J, Qu J, Lei P, Liu H (2004) New bipolar electrocoagulation-electroflotation process for the treatment of laundry wastewater. Sep Purif Technol 36:33-39. https://doi.org/10.1016/S1383-5866(03)00150-3

26. Šostar-Turk S, Petrinić I, Simonič M (2005) Laundry wastewater treatment using coagulation and membrane filtration. Resour Conserv Recycl 44:185-196. https://doi.org/10.1016/j.resconrec.2004.11.002

27. Giagnorio M, Søtoft LF, Tiraferri A, Gruttner H (2017) Ultrafiltration to reuse laundering wash water: evaluation of membranes and permeate flux. Desalination Water Treat 62:22-30. https://doi.org/10.5004/ dwt.2017.20133

28. Matsuo T, Nishi T (2000) Activated carbon filter treatment of laundry waste water in nuclear power plants and filter recovery by heating in vacuum. Carbon 38:709-714. https://doi.org/10.1016/S0008-6223(99) $00158-\mathrm{X}$

29. Jones RJ (2001) Laundry wash-cycle water recovery system

30. Patil VV, Gogate PR, Bhat AP, Ghosh PK (2020) Treatment of laundry wastewater containing residual surfactants using combined approaches based on ozone, catalyst and cavitation. Sep Purif Technol 239: 116594. https://doi.org/10.1016/j.seppur.2020.116594

31. Ciabatti I, Cesaro F, Faralli L, Fatarella E, Tognotti F (2009) Demonstration of a treatment system for purification and reuse of laundry wastewater. Desalination 245:451-459. https://doi.org/10.1016/j.desal. 2009.02.008

32. Ahmad J, EL-Dessouky H (2008) Design of a modified low cost treatment system for the recycling and reuse of laundry waste water. Resour Conserv Recycl 52:973-978. https://doi.org/10.1016/j.resconrec.2008. 03.001

33. Prodanovic V, Hatt B, McCarthy D, Zhang K, Deletic A (2017) Green walls for greywater reuse: Understanding the role of media on pollutant removal. Ecol Eng 102:625-635. https://doi.org/10.1016/j. ecoleng.2017.02.045

34. Gotoh K (2010) Investigation of optimum liquid for textile washing using artificially soiled fabrics. Text Res J 80:548-556. https://doi.org/10.1177/0040517509340605

35. Rojvoranun S, Chadavipoo C, Pengjun W, Chavadej S, Scamehorn JF, Sabatini DA (2012) Mechanistic studies of particulate soil detergency: I. Hydrophobic Soil Removal J Surfactants Deterg 15:277-289. https://doi.org/10.1007/s11743-011-1319-7 
36. Luthander R, Widén J, Nilsson D, Palm J (2015) Photovoltaic self-consumption in buildings: a review. Appl Energy 142:80-94. https://doi.org/10.1016/j.apenergy.2014.12.028

37. AISE (2013) A.I.S.E. Arbeitsgruppe "Waschmittel Prüfungen" - Mindestanforderungen für vergleichende Waschmitteltests. v.5

38. Buehler D, Schuetze T, Junge R (2015) Towards development of a label for zero emission buildings: a tool to evaluate potential zero emission buildings. Sustainability 7:5071-5093. https://doi.org/10.3390/ su7055071

39. Anwar AHMF (2011) Effect of laundry greywater irrigation on soil properties. J Environ Res Dev 5:863-869

40. Misra RK, Sivongxay A (2009) Reuse of laundry greywater as affected by its interaction with saturated soil. J Hydrol 366:55-61. https://doi.org/10.1016/j.jhydrol.2008.12.010

41. Misra RK, Patel JH, Baxi VR (2010) Reuse potential of laundry greywater for irrigation based on growth, water and nutrient use of tomato. J Hydrol 386:95-102. https://doi.org/10.1016/j.jhydrol.2010.03.010

42. Mohamed RM, Al-Gheethi AA, Noramira J, Chan CM, Hashim MKA, Sabariah M (2018) Effect of detergents from laundry greywater on soil properties: a preliminary study. Appl Water Sci 8:16. https://doi. org/10.1007/s13201-018-0664-3

43. Braga JK, Varesche MBA (2014) Commercial laundry water characterisation. Am J Anal Chem 05:8-16. https://doi.org/10.4236/ajac.2014.51002

44. Gattlen J, Amberg C, Zinn M, Mauclaire L (2010) Biofilms isolated from washing machines from three continents and their tolerance to a standard detergent. Biofouling 26:873-882. https://doi.org/10.1080/ 08927014.2010 .524297

45. Zhang X, Li J, Yu Y, Xu R, Wu Z (2016) Biofilm characteristics in natural ventilation trickling filters (NVTFs) for municipal wastewater treatment: Comparison of three kinds of biofilm carriers. Biochem Eng $\mathrm{J}$ 106:87-96. https://doi.org/10.1016/j.bej.2015.11.009

46. Tatoulis T, Stefanakis A, Frontistis Z, Akratos CS, Tekerlekopoulou AG, Mantzavinos D, Vayenas DV (2017) Treatment of table olive washing water using trickling filters, constructed wetlands and electrooxidation. Environ Sci Pollut Res 24:1085-1092. https://doi.org/10.1007/s11356-016-7058-6

47. Chang W-S, Tran H-T, Park D-H, Zhang R-H, Ahn D-H (2009) Ammonium nitrogen removal characteristics of zeolite media in a Biological Aerated Filter (BAF) for the treatment of textile wastewater. J Ind Eng Chem 15:524-528. https://doi.org/10.1016/j.jiec.2009.01.009

48. Lauderdale C, Chadik P, Kirisits MJ, Brown J (2012) Engineered biofiltration: enhanced biofilter performance through nutrient and peroxide addition. J AWWA 104:E298-E309. https://doi.org/10.5942/jawwa. 2012.104.0073

49. Ruiz G, Jeison D, Chamy R (2003) Nitrification with high nitrite accumulation for the treatment of wastewater with high ammonia concentration. Water Res 37:1371-1377. https://doi.org/10.1016/S00431354(02)00475-X

50. Carmassi G, Incrocci L, Maggini R, Malorgio F, Tognoni F, Pardossi A (2005) Modeling salinity build-up in recirculating nutrient solution culture. J Plant Nutr 28:431-445. https://doi.org/10.1081/PLN-200049163

51. Dolnicar S, Hurlimann A, Grün B (2011) What affects public acceptance of recycled and desalinated water? Water Res 45:933-943. https://doi.org/10.1016/j.watres.2010.09.030

52. Boano F, Caruso A, Costamagna E, Ridolfi L, Fiore S, Demichelis F, Galvão A, Pisoeiro J, Rizzo A, Masi F (2020) A review of nature-based solutions for greywater treatment: Applications, hydraulic design, and environmental benefits. Sci Total Environ 711:134731. https://doi.org/10.1016/j.scitotenv.2019.134731

53. Rysulova M, Kaposztasova D, Vranayova Z (2017) Green walls as an approach in grey water treatment. IOP Conf Ser Mater Sci Eng 245:072049. https://doi.org/10.1088/1757-899X/245/7/072049 